\title{
Review: lithium is effective in preventing relapse in mixed diagnoses of mood disorder and in bipolar disorder
}

\author{
Burgess S, Geddes J, Hawton K, et al. Lithium for maintenance treatment of mood disorders. Cochrane Database Syst Rev \\ 2001;(4):CD003013 (latest version Mar 19 2001).
}

Source of funding: south east Region NHSE Research and Development UK

For correspondence: DrJ Geddes, University of Oxford, Warneford Hospital, Oxford, UK. john.geddes@

\section{QUESTION: In patients with mood disorders, what is the efficacy of lithium compared with placebo?} psychiatry.oxford.ac.uk

\section{Data sources}

Studies were identified by searching the Cochrane Collaboration Depression, Anxiety and Neurosis Controlled Trials Register and the Cochrane Controlled Trials Register; reviewing the reference lists of relevant papers

Lithium v placebo in mood disorders*

\begin{tabular}{lllll}
$\begin{array}{l}\text { Outcomes covering } \\
\text { up to } 4 \text { years }\end{array}$ & Lithium & Placebo & RRR (95\% CI) & NNT (CI) \\
\hline Relapse - all mood disorders & $38 \%$ & $67 \%$ & $46 \%(30$ to 58$)$ & 3 (2 to 5$)$ \\
\hline Relapse - bipolar disorder only & $36 \%$ & $61 \%$ & $40 \%(13$ to 59$)$ & 4 (2 to 30$)$ \\
\hline
\end{tabular}

*Abbreviations defined in glossary; RRR, NNT, and Cl calculated from data in article.

\section{COMMENTARY}

Compared with the prevalence and severity of bipolar disorder, the evidence base for treatment decisions in bipolar disorder is limited. This Cochrane review convincingly documents the efficacy of lithium prophylaxis. No other treatment for this indication has similar research basis. This, however, is not the full story. Many observational studies have failed to confirm the effectiveness of lithium prophylaxis, or indicated that only a minority of eligible patients will comply with or respond to long term treatment. ${ }^{12}$ Reasons are many, including both well known adverse effects, subtle neuropsychological consequences, lack of insight into the chronic nature of the disorder, and in some cases, possibly the positive effects of hypomania and the generally elusive hope of controlling mental stability without psychotropic medication.

Cognitive behavioural therapy, compliance training, and family intervention have all shown some promising results, but are still in an early phase of development. Combined therapy with anticonvulsants, benzodiazepines, antipsychotics and antidepressive drugs are widely applied, but the research bases for these are almost non-existent.

Currently, the practical approach includes a focus on the patient doctor relationship, including significant others in the decision process, and sensitivity for patient reported adverse effects with a flexibility for dose adjustment. Alcohol and drug abuse is a common complication and must be addressed separately.

Since valproic acid is the best studied alternative for acute mania, it seems rational to try this first when lithium is ineffective or poorly tolerated. This is so, even if the only long term comparison showed little effect for either valproate or lithium. ${ }^{3}$

Sten Thelander, MD Swedish Council on Technology Assessment in Health Care Stockholm, Sweden

1 Keck PE Jr, McElroy SL, Strakowski SM, et al. Compliance with maintenance treatment in bipolar disorder. Psychopharmacol Bull 1997;33:87-91.

2 Maj M, Pirozzi R, Magliano L, et al. Long-term outcome of lithium prophylaxis in bipolar disorder: a 5-year prospective study of 402 patients at a lithium clinic. Am J Psychiatry 1998; 155:30-5

3 Bowden CL, Calabrese JR, McElroy SL, et al. A randomized, placebo-controlled 12-month trial of divalproex and lithium in treatment of outpatients with bipolar I disorder. Divalproex Maintenance Study Group. Arch Gen Psychiatry 2000;57:481-9. See: http://www.ebmentalhealth.com/cgi/content/full/4/1/9 and text books; hand searching the journals Lithium (1990-4) and Lithium Therapy Monographs (1987-91); and contacting authors, pharmaceutical companies, and experts in the field.

\section{Study selection}

Studies were selected if they were randomised controlled trials comparing lithium with placebo with the stated intent of treatment being maintenance or prophylaxis. Discontinuation studies were excluded.

\section{Data extraction}

Data were extracted by 2 independent reviewers on study quality, patient characteristics, intervention type and dose, and the main outcome measures.

\section{Main results}

9 studies met the selection criteria involving 825 patients. Quantitative heterogeneity existed among the studies. Thus, a random effects model was used when combining data. Lithium (dose between 0.5 and 1.4 $\mathrm{mmol} / \mathrm{l}$ ) was found to be more effective than placebo in preventing relapse (relapse however defined) in mood disorder overall (unipolar, bipolar, and unspecified) and in bipolar disorder (table). In unipolar disorder, the direction of effect was in favour of lithium, but the result did not reach statistical significance. Few studies included data on general health and social functioning, and when they did, the data were absent or inadequately reported. Small absolute numbers of deaths and suicides, and the absence of data on non-fatal suicidal behaviours, made it impossible to draw meaningful conclusions about the place of lithium in suicide prevention.

\section{Conclusion}

For mixed diagnoses of mood disorder and in bipolar disorder lithium is more effective than placebo in preventing relapse. 